\title{
Comparison of Surgical Outcomes Between Two Types of Lamellar Macular Holes
}

This article was published in the following Dove Press journal:

Clinical Ophthalmology

\section{Shumpei Obata $\mathbb{D}$ \\ Yusuke Ichiyama (D) \\ Masashi Kakinoki \\ Osamu Sawada (iD) \\ Yoshitsugu Saishin \\ Masahito Ohji}

Department of Ophthalmology, Shiga University of Medical Science, Shiga, Japan
Purpose: The classification of lamellar macular holes (LMHs) into two subtypes has recently been proposed. However, the effectiveness of vitrectomy for treatment of each type of LMH is not well established. The goal of this study was to compare functional and anatomic changes after vitrectomy between eyes with degenerative LMH and those with tractional LMH.

Patients and methods: This was a retrospective analysis of the medical records of patients with LMH who underwent vitrectomy. Best-corrected visual acuity (BCVA) and central macular thickness (CMT) were measured preoperatively (baseline), as well as at 1, 3 and 12 months postoperatively. BCVA and CMT were compared between eyes with degenerative LMH and those with tractional LMH.

Results: Thirty-two eyes met the inclusion criteria. Thirteen eyes were diagnosed with degenerative LMH and 19 eyes were diagnosed with tractional LMH. Compared with baseline BCVA, postoperative BCVA improved significantly at 12 months postoperatively: from 0.33 to 0.12 logarithm of the minimum angle of resolution (logMAR) in eyes with degenerative LMH and from 0.30 to $0.12 \log$ MAR in eyes with tractional $\mathrm{LMH}$ ( $\mathrm{p}<0.05$ for both comparisons). BCVA at 12 months postoperatively did not significantly differ between the two groups. CMT decreased significantly from $419.4 \mu \mathrm{m}$ at baseline to $364.2 \mu \mathrm{m}$ at 12 months postoperatively in eyes with tractional LMH $(\mathrm{p}<0.05)$; conversely, there was no significant difference in eyes with degenerative LMH $(315.5 \mu \mathrm{m}$ baseline to $314.9 \mu \mathrm{m}$ at 12 months postoperatively; $\mathrm{p}>0.05$ ).

Conclusion: Vitrectomy improved BCVA in eyes with degenerative LMH as well as in eyes with tractional LMH. BCVA at 12 months postoperatively did not differ between the two groups.

Keywords: lamellar macular hole, surgery, visual acuity, ellipsoid zone

\section{Introduction}

Lamellar macular holes (LMHs) were first described by Gass in $1976 .{ }^{1}$ LMHs cause visual loss and metamorphopsia. Patients with LMH typically exhibit relative preservation of visual acuity (VA), compared with the less-favorable vision experienced by patients with a full-thickness macular hole. ${ }^{2,3}$ Visual outcomes have not been consistent after surgery for $\mathrm{LMH}^{3-7}$ Some investigators have assessed the preoperative status and surgical procedures for LMHs. Lamellar hole-associated epiretinal proliferation (LHEP) has been associated with morphological changes. $^{6,8,9}$ Inner limiting membrane (ILM) peeling during surgery is an effective treatment for $\mathrm{LMH} .{ }^{10,11}$ However, air/gas tamponade is known to be effective for improving central macular thickness (CMT) but does not positively impact VA. ${ }^{11,12}$
Correspondence: Shumpei Obata Shiga University of Medical Science, 520 2192, Seta Tsukinowacho, Otsu City, Shiga, Japan

Tel $+81-77-548-2276$

Fax +8I-77-548-2279

Email obata326@belle.shiga-med.ac.jp 
Preoperative disruption of the ellipsoid zone (EZ) is associated with poor postoperative visual outcome. ${ }^{11,13}$ The classification of LMHs into two subtypes has been recently proposed, comprising degenerative and tractional types. ${ }^{14}$ There has been only one report comparing the effectiveness of vitrectomy between tractional and degenerative LMHs; it showed that VA was improved for tractional LMHs, but not for degenerative LMHs. ${ }^{10}$ However, the effectiveness of vitrectomy for each type of $\mathrm{LMH}$ is not well established. In this study, we compared VA and morphologic surgical outcomes between eyes with degenerative $\mathrm{LMH}$ and those with tractional $\mathrm{LMH}$. We also compared preoperative and postoperative best-corrected visual acuity (BCVA) in degenerative and tractional LMHs, based on the presence of EZ disruption, presence of LHEP, and use of air/gas tamponade.

\section{Materials and Methods}

This study protocol (IRB\# 30-069) was approved by the Institutional Review Board (IRB)/Ethics Committee Shiga University of Medical Science (Otsu, Japan). For this type of retrospective study, an opt-out consent process was used at Shiga University of Medical Science Hospital; no optout was used at Soseikai General Hospital, following approval by the IRB. This study adhered to the tenets of the Declaration of Helsinki. The medical records of patients who underwent vitrectomy to treat $\mathrm{LMH}$ from January 2011 to December 2017 at Shiga University of Medical Science Hospital and Soseikai General Hospital were retrospectively reviewed. All patients had undergone vitrectomy to treat $\mathrm{LMH}$ if they suffered from visual loss and/or metamorphopsia. There were no limitations regarding preoperative visual acuity. Patients were included in the study if they had been followed for at least 3 months and did not meet any of the following exclusion criteria: the presence of high myopia of $\geq 6$ diopters (D); poor signal strength of $\leq 5$ on optical coherence tomography (OCT) (Cirrus OCT, Carl Zeiss Meditec, Dublin, CA, USA) at baseline and at 1, 3, and 12 months postoperatively; history of previous vitreous surgery; presence of any other retinal disease; and postoperative complication.

Main outcome measures were postoperative logarithm of minimal angle of resolution (logMAR) BCVA and CMT. The subjects were divided into two groups: degenerative $\mathrm{LMH}$ and tractional $\mathrm{LMH}$, in accordance with the classification by Govetto et al. If the lesion did not definitively match either category, it was classified as "mixed". ${ }^{14}$ Preoperative and postoperative BCVA, CMT, and metamorphopsia were compared between the two LMH groups.

Secondary outcome measures were the effects of EZ disruption, LHEP, and air/gas tamponade use on preoperative and postoperative BCVA in eyes with degenerative or tractional LMHs.

The following data were collected from medical charts and OCT images: patient age, sex, operated eye, preoperative BCVA, preoperative CMT, preoperative presence of EZ disruption, preoperative presence of LHEP, preoperative phakic/pseudophakic status, and surgical technique used. BCVA was measured using a Landolt $\mathrm{C}$ chart and was converted to the $\log$ MAR equivalent for statistical analysis at baseline, as well as at 1, 3 and 12 months postoperatively. CMT was defined as the distance between the vitreoretinal interface and the inner border of the retinal pigment epithelium (RPE), in accordance with the OCT-device manufacturer's definition. CMT was measured using the RT map analysis protocol in the OCT instrument at baseline, as well as at 1,3 and 12 months postoperatively.

A standard 25-gauge pars plana vitrectomy was performed for all patients. Phacoemulsification and intraocular lens implantation were performed prior to vitrectomy in all phakic eyes. Triamcinolone acetonide (MaQaid, Wakamoto Pharmaceutical Co., Ltd., Tokyo, Japan) was injected into the vitreous cavity after core vitrectomy to enable visualization of the epiretinal membrane (ERM), which was peeled from the macular area with end-gripping forceps in some patients. After the ERM had been completely peeled, Brilliant Blue G (BBG, Brilliant Peel ${ }^{\mathrm{TM}}$ $0.25 \mathrm{mg} / \mathrm{mL}$, Fluoron, Ulm, Germany) was sprayed gently on the macular area to detect the ILM, which was peeled from the macular area in all patients. Air/gas tamponade was performed at the surgeon's discretion.

Statistical analyses were performed using GraphPad Prism 6 software (GraphPad Software, Inc., La Jolla, CA, USA). The results were expressed as the mean \pm standard deviation for continuous variables and as proportions (\%) for categorical variables. The Mann-Whitney $U$-test was used for two-group comparisons of independent and matched groups. Spearman correlation coefficients were assessed to determine the relationships between postoperative BCVA and each of the preoperative factors. Differences with $\mathrm{p}<0.05$ were considered to be statistically significant.

\section{Results}

Thirty-two eyes with symptomatic LMH that underwent surgical treatment in the participating hospitals met the 
above-mentioned inclusion/exclusion criteria. Twenty-four patients were women (75\%). The median patient age was 70 (mean 68.7, range 42-88) years. Right eyes underwent surgery in 19 patients (59\%). Thirteen eyes had degenerative LMH (41\%); 19 eyes had tractional LMH (59\%); no eyes were diagnosed as mixed type. Examples of typical cases of the two types of LMH are shown in Figure 1. LHEP was present in 12 eyes (37.5\%). EZ disruption was detected in 10 eyes $(31.3 \%)$ (Table 1$)$. Twelve of 13 eyes with degenerative $\mathrm{LMH}$ and 19 of 19 eyes with tractional LMH underwent cataract surgery; however, there were no cataracts that were considered significant enough to have caused visual loss. Twenty-four eyes underwent air/gas tamponade during the surgery (Table 2).

\section{Visual Acuity}

Across all of the eyes, preoperative mean BCVA was $0.31 \pm 0.18 \log$ MAR, while postoperative mean BCVA was $0.12 \pm 0.20 \log$ MAR; this difference was statistically significant $(\mathrm{p}=0.0002)$. Regarding changes in BCVA on the basis of type of LMH, VA had significantly improved at 12 months postoperatively in eyes with degenerative LMH $(0.30 \pm 0.15 \log$ MAR to $0.12 \pm 0.22 \log$ MAR; $\mathrm{p}=0.007$; Figure 2), as well as in those with tractional $\mathrm{LMH}(0.33 \pm 0.24 \log \mathrm{MAR}$ to $0.11 \pm 0.17 \log \mathrm{MAR}$;
Table I Baseline Characteristics of Patients (Eyes) in This Study

\begin{tabular}{|l|l|l|l|}
\hline & $\begin{array}{l}\text { Degenerative } \\
\text { Type }\end{array}$ & $\begin{array}{l}\text { Tractional } \\
\text { Type }\end{array}$ & P-value \\
\hline Eyes & 13 & 19 & \\
Sex (male: female) & $4: 9$ & $4: 15$ & 0.68 \\
Age (years) & 66.2 & 70.3 & 0.35 \\
LogMAR BCVA & $0.33 \pm 0.24$ & $0.30 \pm 0.15$ & 0.98 \\
CMT ( $\mu \mathrm{m})$ & $315.5 \pm 57.4$ & $419.4 \pm 80.3$ & $<0.0001$ \\
LHEP (+: -) & $9: 4$ & $3: 16$ & 0.0023 \\
Disruption of EZ (+: -) & $7: 6$ & $3: 16$ & 0.049 \\
\hline
\end{tabular}

Abbreviations: logMAR BCVA, logarithm of the minimum angle of resolution best-corrected visual acuity; CMT, central macular thickness; LHEP, lamellar holeassociated epiretinal proliferation; EZ, ellipsoid zone.

$\mathrm{p}=0.01$; Figure 2). Notably, 12-month postoperative BCVA was not significantly different between the two groups. Compared with BCVA at 1 month postoperatively, BCVA improved significantly at 12 months postoperatively, from 0.19 to $0.12 \log$ MAR in eyes with degenerative LMH $(\mathrm{p}=0.04)$ and from 0.31 to $0.12 \log$ MAR in eyes with tractional LMH $(\mathrm{p}=0.002)$.

\section{OCT Findings}

Preoperative mean CMT was $377.2 \pm 89.0 \mu \mathrm{m}$, while postoperative mean CMT was $345.5 \pm 71.4 \mu \mathrm{m}$; this difference was not statistically significant $(\mathrm{p}>0.05)$. Regarding

\section{Degenerative type}
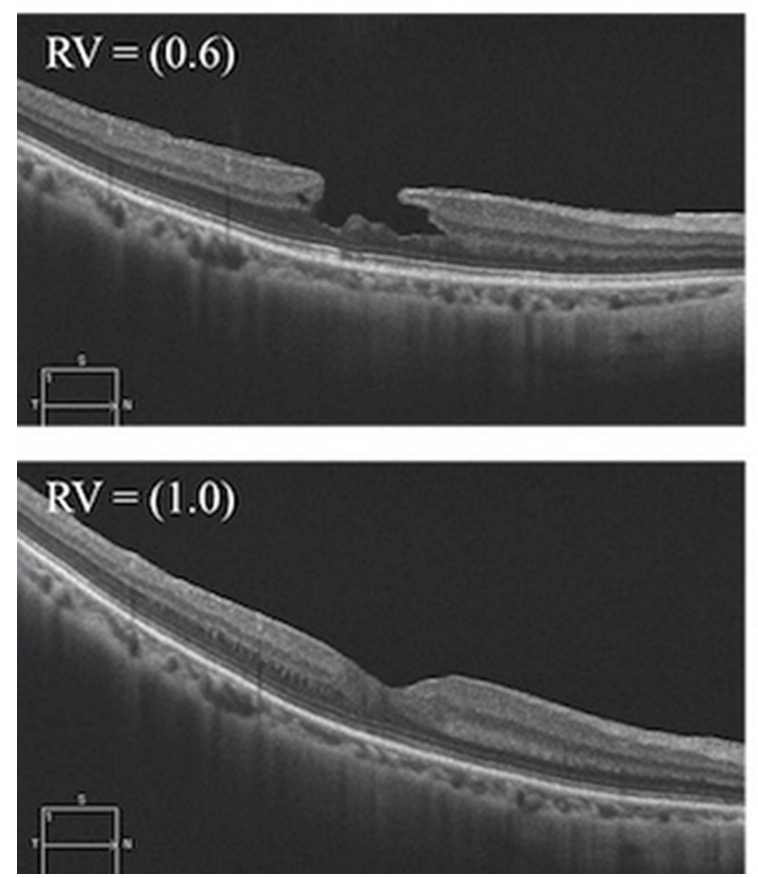

\section{Tractional type}
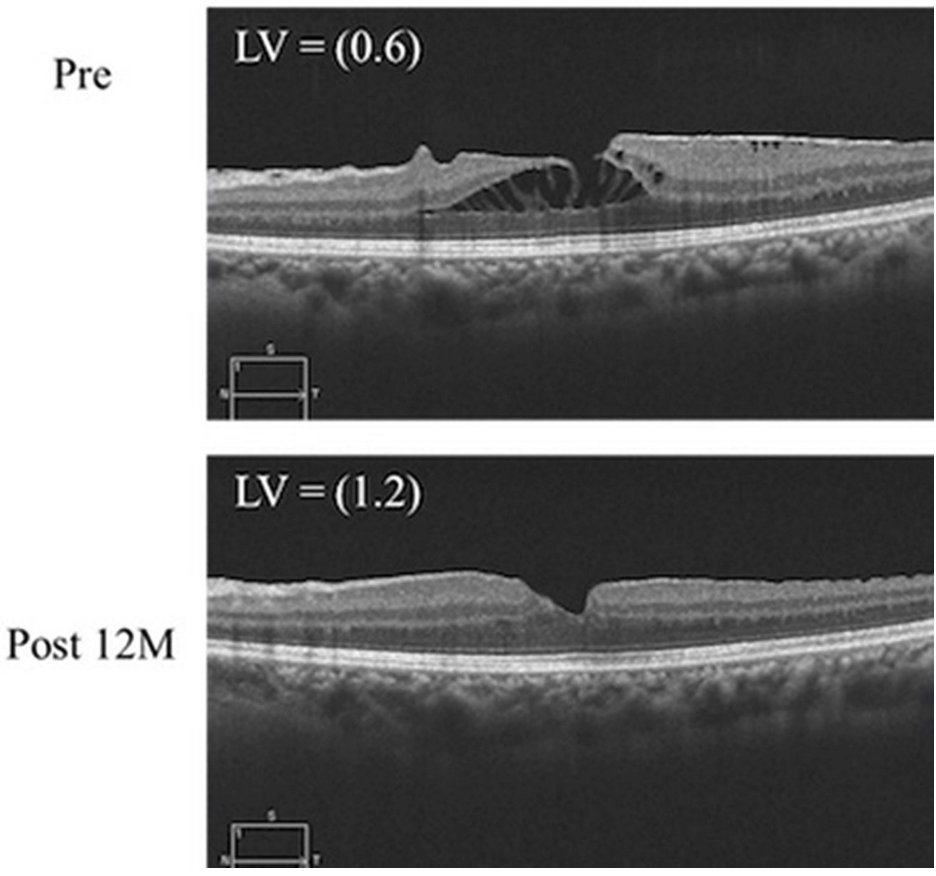

Figure I Typical preoperative and postoperative optical coherence tomography images for the two types of lamellar macular holes. 
Table 2 Surgical Procedures for Eyes in This Study

\begin{tabular}{|l|l|l|l|}
\hline & $\begin{array}{l}\text { Degenerative } \\
\text { Type }\end{array}$ & $\begin{array}{l}\text { Tractional } \\
\text { Type }\end{array}$ & P value \\
\hline Eyes & 13 & 19 & - \\
ILM peeling (eyes) & 13 & 19 & - \\
Cataract surgery (eyes) & 12 & 19 & - \\
$\begin{array}{l}\text { Air/gas tamponade } \\
\text { (eyes) (+: -) }\end{array}$ & $11: 2$ & $13: 6$ & 0.42 \\
\hline
\end{tabular}

Abbreviation: ILM, inner limiting membrane.

changes in CMT on the basis of type of LMH, CMT had significantly decreased at 12 months postoperatively in eyes with tractional LMH $(414.9 \pm 82.5 \mu \mathrm{m}$ to $364.2 \pm 70.9 \mu \mathrm{m}$; $\mathrm{p}=0.01)$, but not in those with degenerative LMH (315.5 \pm $57.4 \mu \mathrm{m}$ to $314.9 \pm 63.8 \mu \mathrm{m} ; \mathrm{p}>0.05$ ) (Figure 3). Postoperatively, there were still three eyes with EZ disruption in the tractional type, but the number in the degenerative type decreased from seven eyes to four.

\section{Factors Affecting Postoperative BCVA in Each Subtype of LMH}

Comparisons of postoperative BCVA based on EZ disruption, LHEP, and tamponade use are shown in Table 3. Postoperative BCVA in patients without EZ disruption was numerically better than that in patients with EZ disruption, but the difference was not statistically significant.

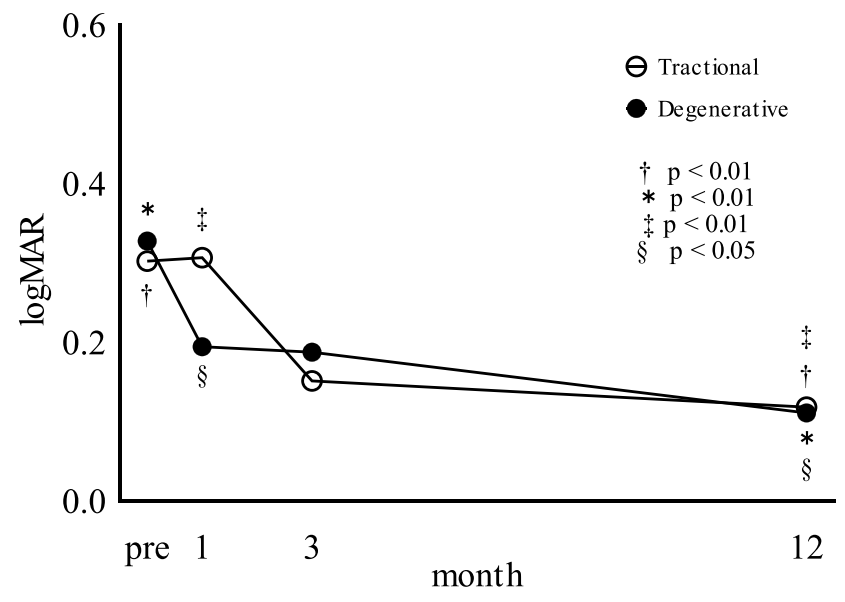

Figure 2 Best-corrected visual acuity (BCVA, in logarithm of the minimum angle of resolution [logMAR]) in eyes with each type of lamellar macular hole (LMH). BCVA significantly improved after surgery in eyes with degenerative $L M H$ and those with tractional LMH. Compared with BCVA at I month postoperatively, BCVA was significantly improved at 12 months postoperatively in eyes with tractional $\mathrm{LMH}$ and those with degenerative LMH. BCVA did not significantly differ between the two groups at 12 months postoperatively.

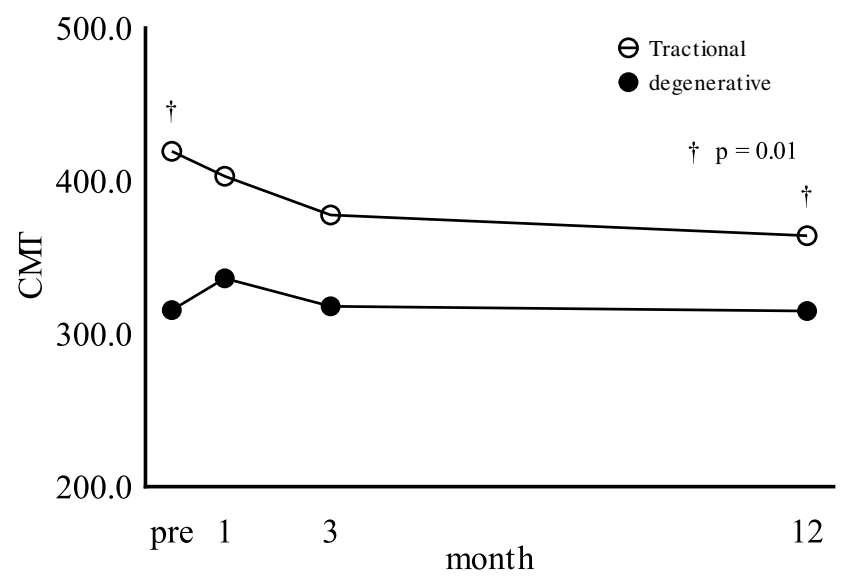

Figure 3 Central macular thickness (CMT) in eyes with each type of lamellar macular hole $(\mathrm{LMH})$. CMT decreased after surgery in eyes with tractional $\mathrm{LMH}$, but not in those with degenerative LMH.

\section{Discussion}

We compared functional and anatomic changes after vitrectomy between eyes with degenerative LMH and those with tractional LMH, in accordance with the classification by Govetto et al. ${ }^{14}$ To the best of our knowledge, this is the first report to show that vitrectomy is effective for improving visual acuity in both tractional and degenerative LMHs; moreover, there were no differences in the improvement of VA between tractional and degenerative LMHs. In another study, BCVA in tractional LMH showed postoperative improvement, whereas degenerative LMH did not. ${ }^{10}$ The postoperative BCVA in tractional LMH showed significant improvement $(\mathrm{p}<0.05)$ from 0.41 to $0.25 \operatorname{logMAR}$; in contrast, postoperative BCVA in degenerative $\mathrm{LMH}$ showed non-significant improvement from 0.61 to $0.54 \log$ MAR. ${ }^{10}$ In contrast to the findings of that previous study, BCVA at 12 months postoperatively in the present study showed significant improvement in both groups ( $\mathrm{p}<0.05$ for both comparisons): from 0.30 to $0.12 \log$ MAR in degenerative $\mathrm{LMH}$ and from 0.33 to $0.11 \log$ MAR in tractional LMH. The findings in previous reports might differ from those in this report because the baseline BCVA of eyes with degenerative LMH was worse in those reports than in our study. Patients with long-term degenerative LMH may have been included in previous reports. BCVA may improve postoperatively if the surgery is performed before severe visual loss. Thus, the difference in baseline characteristics might have led to different results. Another explanation was that number of cases with disruption of the EZ in this study (53.8\%) was smaller than that in the study by Govetto et al $(95.83 \%) .{ }^{14} \mathrm{In}$ this study, the number of eyes with EZ disruption in the 
Table 3 Comparison of Pre- and Postoperative Logarithm of the Minimum Angle of Resolution Best-Corrected Visual Acuity (Log MAR BCVA) Between Presence and Absence of Disruption of Ellipsoid Zone (EZ), Presence of Lamellar Hole-Associated Epiretinal Proliferation (LHEP), and Use of Air/Gas Tamponade in Degenerative or Tractional Type Lamellar Macular Holes

\begin{tabular}{|c|c|c|c|c|c|c|}
\hline & \multicolumn{2}{|l|}{ Disruption of EZ } & \multicolumn{2}{|l|}{ LHEP } & \multicolumn{2}{|c|}{ Air/Gas Tamponade } \\
\hline \multicolumn{7}{|l|}{ Degenerative type } \\
\hline & Presence $(n=7)$ & Absence $(n=6)$ & Presence $(n=9)$ & Absence $(n=4)$ & Presence $(n=11)$ & Presence $(n=2)$ \\
\hline Pre LogMAR BCVA & $0.34 \pm 0.34$ & $0.32 \pm 0.13$ & $0.36 \pm 0.28$ & $0.25 \pm 0.18$ & $0.34 \pm 0.25$ & $0.25 \pm 0.21$ \\
\hline Post I2M LogMAR BCVA & $0.19 \pm 0.17$ & $-0.003 \pm 0.08$ & $0.09 \pm 0.16$ & $0.16 \pm 0.20$ & $0.14 \pm 0.17$ & $-0.02 \pm 0.09$ \\
\hline \multicolumn{7}{|l|}{ Tractional type } \\
\hline & Presence $(n=3)$ & Absence $(n=16)$ & Presence $(n=3)$ & Absence $(n=16)$ & Presence $(n=13)$ & Presence $(n=6)$ \\
\hline Pre LogMAR BCVA & $0.26 \pm 0.13$ & $0.31 \pm 0.16$ & $0.41 \pm 0.11$ & $0.28 \pm 0.15$ & $0.29 \pm 0.11$ & $0.33 \pm 0.22$ \\
\hline Post I2M LogMAR BCVA & $0.30 \pm 0.27$ & $0.08 \pm 0.20$ & $0.23 \pm 0.27$ & $0.10 \pm 0.22$ & $0.10 \pm 0.21$ & $0.16 \pm 0.26$ \\
\hline
\end{tabular}

degenerative type decreased from seven eyes to four eyes postoperatively. Preoperative disruption of the EZ can be repaired after ERM surgery. ${ }^{15,16}$ The preoperative proportion of eyes with EZ disruption and the improvement in the EZ in degenerative type eyes might have contributed to the better postoperative visual acuity in the degenerative type.

CMT decreased after surgery in tractional $\mathrm{LMH}$, but not in degenerative LMH. These results were similar to those of a previous report. ${ }^{10}$ The cause of higher mean CMT in tractional LMH might have been foveal traction related to the ERM; in contrast, mean CMT in degenerative LMH might have been lower because tractional power is lower without ERM. The fact that CMT in degenerative LMH was nearly normal preoperatively might account for the minimal change between baseline and postoperative measurements.

Postoperative BCVA in patients without EZ disruption was numerically better than that in patients with EZ disruption, although the difference was not statistically significant. The finding regarding EZ disruption was similar to that of a previous report. ${ }^{13}$ The presence of a disrupted inner segment / outer segment junction on preoperative spectral-domain OCT predicted poor visual outcome after LMH surgery. ${ }^{13}$ The presence of LHEP and use of tamponade did not significantly influence postoperative BCVA (Table 3). In another report, BCVA significantly improved after surgery in eyes without LHEP $(p<0.001)$ but showed no change in eyes with LHEP $(\mathrm{p}=0.185) .{ }^{17}$ In that report, initial BCVA did not differ between the two groups; however, final BCVA was better in eyes without LHEP $(0.10 \pm 0.10 \operatorname{logMAR}$ vs $0.33 \pm 0.40 \operatorname{logMAR}$; $\mathrm{p}=0.003) .{ }^{17}$ There remains controversy regarding the removal of LHEP during surgery. The difference between the findings of this report and those of the previous report is unknown; however, the surgical technique might have influenced the results.

This study had some limitations. This study was retrospective and short term and had a small sample size. Furthermore, phacoemulsification and intraocular lens implantation were performed concurrently with vitrectomy in all phakic eyes, which might have influenced the results of this study, although the effect seemed to be minimal because the preoperative cataracts were mild in all eyes. Although visual improvement due to cataract surgery could not be completely excluded, postoperative BCVA at 12 months was significantly improved compared with postoperative BCVA at 1 month, which supports improvement of BCVA resulting from the vitrectomy, not just the cataract surgery. In addition to the improvement in BCVA, EZ improved postoperatively in some cases, which may also support functional improvement. Thus, the effect of cataract surgery was limited.

\section{Conclusion}

Vitrectomy was effective for the improvement of visual function in eyes with tractional LMH and those with degenerative LMH.

\section{Abbreviations}

BCVA, best-corrected visual acuity; CMT, central macular thickness; ERM, epiretinal membrane; EZ, ellipsoid zone; ILM, inner limiting membrane; IRB, Institutional Review Board; LHEP, lamellar hole-associated epiretinal proliferation; LMHs, lamellar macular holes; logMAR, logarithm of 
minimal angle of resolution; OCT, optical coherence tomography; RPE, retinal pigment epithelium; VA, visual acuity.

\section{Acknowledgment}

We thank Ryan Chastain-Gross, Ph.D., from Edanz Group, for editing a draft of this manuscript.

\section{Disclosure}

The authors report no conflicts of interest in this work.

\section{References}

1. Gass JD. Lamellar macular hole: a complication of cystoid macular edema after cataract extraction: a clinicopathologic case report. Trans Am Ophthalmol Soc. 1975;73:231-250.

2. Theodossiadis PG, Grigoropoulos VG, Emfietzoglou I, et al. Evolution of lamellar macular hole studied by optical coherence tomography. Graefes Arch Clin Exp Ophthalmol. 2009;247(1):13-20. doi:10.1007/ s00417-008-0927-z

3. Casparis H, Bovey EH. Surgical treatment of lamellar macular hole associated with epimacular membrane. Retina. 2011;31(9):1783-1790. doi:10.1097/IAE.0b013e31820a6818

4. Haouchine B, Massin P, Tadayoni R, Erginay A, Gaudric A. Diagnosis of macular pseudoholes and lamellar macular holes by optical coherence tomography. Am J Ophthalmol. 2004;138(5):732-739. doi:10.10 16/j.ajo.2004.06.088

5. Hirakawa M, Uemura A, Nakano T, Sakamoto T. Pars plana vitrectomy with gas tamponade for lamellar macular holes. $\mathrm{Am}$ J Ophthalmol. 2005;140(6):1154-1155. doi:10.1016/j.ajo.2005.07.022

6. Witkin AJ, Ko TH, Fujimoto JG, et al. Redefining lamellar holes and the vitreomacular interface: an ultrahigh-resolution optical coherence tomography study. Ophthalmology. 2006;113(3):388-397. doi:10.10 16/j.ophtha.2005.10.047

7. Figueroa MS, Noval S, Contreras I. Macular structure on optical coherence tomography after lamellar macular hole surgery and its correlation with visual outcome. Can J Ophthalmol. 2011;46(6):4 91-497. doi:10.1016/j.jcjo.2011.09.011
8. Parolini B, Schumann RG, Cereda MG, Haritoglou C, Pertile G. Lamellar macular hole: a clinicopathologic correlation of surgically excised epiretinal membranes. Invest Ophthalmol Vis Sci. 2011;52 (12):9074-9083. doi:10.1167/iovs.11-8227

9. Bottoni F, Deiro AP, Giani A, Orini C, Cigada M, Staurenghi G. The natural history of lamellar macular holes: a spectral domain optical coherence tomography study. Graefes Arch Clin Exp Ophthalmol. 2013;251(2):467-475. doi:10.1007/s00417-012-2044-2

10. Coassin M, Mastrofilippo V, Stewart JM, et al. Lamellar macular holes: surgical outcome of 106 patients with long-term follow-up. Graefes Arch Clin Exp Ophthalmol. 2018;256(7):1265-1273. doi:10. 1007/s00417-018-3989-6

11. Sun JP, Chen SN, Chuang CC, et al. Surgical treatment of lamellar macular hole secondary to epiretinal membrane. Graefes Arch Clin Exp Ophthalmol. 2013;251(12):2681-2688. doi:10.1007/s00417-0132364-x

12. Sato T, Emi K, Bando H, Ikeda T. Retrospective comparisons of vitrectomy with and without air tamponade to repair lamellar macular hole. Ophthalmic Surg Lasers Imaging Retina. 2015;46(1):38-43. doi:10.3928/23258160-20150101-06

13. Lee CS, Koh HJ, Lim HT, Lee KS, Lee SC. Prognostic factors in vitrectomy for lamellar macular hole assessed by spectral-domain optical coherence tomography. Acta Ophthalmol. 2012;90(8):e597602. doi:10.1111/j.1755-3768.2012.02456.x

14. Govetto A, Dacquay Y, Farajzadeh M, et al. Lamellar macular hole: two distinct clinical entities? Am J Ophthalmol. 2016;164:99-109. doi:10.1016/j.ajo.2016.02.008

15. Mariko I, Akira A, Shin Y, et al. Long-term outcome of preoperative disrupted inner/outer segment junctions assessed using spectral-domain optical coherence tomography in patients with idiopathic epiretinal membrane. Ophthalmologica. 2012;228(4):222-228. doi:10.1159/000341606

16. Kim HJ, Kang JW, Chung H, et al. Correlation of foveal photoreceptor integrity with visual outcome in idiopathic epiretinal membrane. Curr Eye Res. 2014;39(6):626-633. doi:10.3109/027136 83.2013.860990

17. Ko J, Kim GA, Lee SC, et al. Surgical outcomes of lamellar macular holes with and without lamellar hole-associated epiretinal proliferation. Acta Ophthalmol. 2017;95(3):e221-6. doi:10.1111/aos. 2017.95.issue-3
Clinical Ophthalmology

\section{Publish your work in this journal}

Clinical Ophthalmology is an international, peer-reviewed journal covering all subspecialties within ophthalmology. Key topics include: Optometry; Visual science; Pharmacology and drug therapy in eye diseases; Basic Sciences; Primary and Secondary eye care; Patient Safety and Quality of Care Improvements. This journal is indexed on PubMed

\section{Dovepress}

Central and CAS, and is the official journal of The Society of Clinical Ophthalmology (SCO). The manuscript management system is completely online and includes a very quick and fair peer-review system, which is all easy to use. Visit http://www.dovepress.com/ testimonials.php to read real quotes from published authors. 